
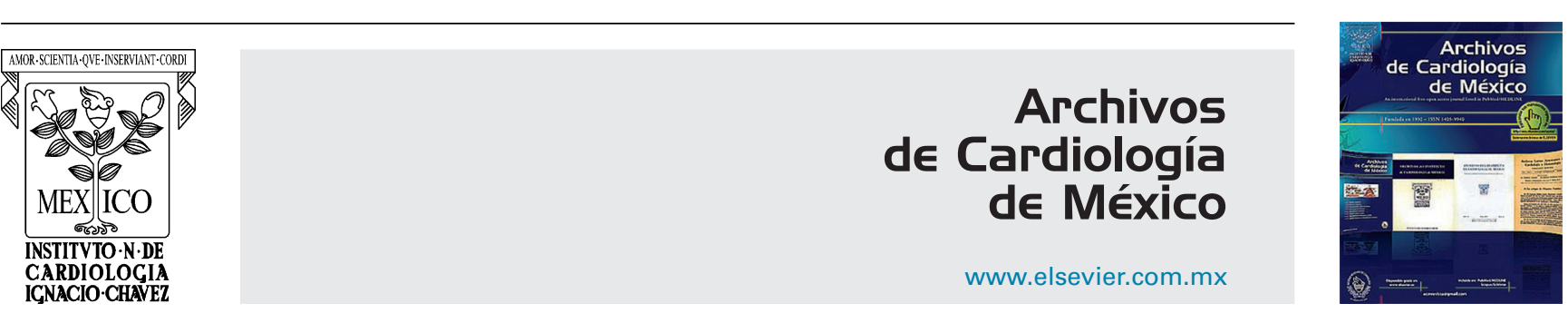

SPECIAL ARTICLE

\title{
Reperfusion of myocardial infarction in India: Notions for México
}

\section{Diego Araiza-Garaygordobil ${ }^{a, *}$, Alexandra Arias-Mendoza ${ }^{a}$, Carlos Martínez-Sánchez ${ }^{a}$, Marco Antonio Martínez-Ríos ${ }^{\mathrm{b}}$, Mullasari S. Ajit ${ }^{\mathrm{c}}$}

\author{
a Instituto Nacional de Cardiología "Ignacio Chávez", Unidad Coronaria, Ciudad de México, Mexico \\ b Instituto Nacional de Cardiología "Ignacio Chávez", Dirección General, Ciudad de México, Mexico \\ c Madras Medical Mission, Cardiology Department, Chennai, Tamil Nadu, India
}

Received 22 July 2017; accepted 24 October 2017

\section{KEYWORDS}

Reperfusion;

Myocardial infarction;

ST elevation

myocardial

infarction;

India;

Developing countries;

México

\section{PALABRAS CLAVE}

Reperfusión;

Infarto del miocardio;

Infarto agudo de

miocardio con

elevación del

segmento ST;

India;

Países en desarrollo;

México

\begin{abstract}
In India and México, cardiovascular diseases are the first cause of death and potential years of life lost. Close similarities exist between these two countries when facing the difficulties to establish a universal reperfusion program for ST elevation myocardial infarction (STEMI). This paper describes the situation of STEMI treatment in both countries, and examines the lessons that Mexico's health care system could adopt from the recent advances accomplished by the STEMI initiative in India.

๑ 2017 Instituto Nacional de Cardiología Ignacio Chávez. Published by Masson Doyma México S.A. This is an open access article under the CC BY-NC-ND license (http://creativecommons. org/licenses/by-nc-nd/4.0/).
\end{abstract}

Reperfusión del Infarto del Miocardio en India: Nociones para México

Resumen En India y México, las enfermedades cardiovasculares constituyen la primera causa de muerte y pérdida de años potenciales de vida. Existen similitudes cercanas entre estos 2 países en cuanto a las dificultades a enfrentar al establecer un programa de reperfusión universal para el infarto agudo de miocardio con elevación del segmento ST (IAMCEST). Este artículo describe la situación del tratamiento del IAMCEST en ambas naciones y explora las lecciones que el sistema de salud de México podría adoptar de los recientes avances logrados por la iniciativa STEMI India.

๑ 2017 Instituto Nacional de Cardiología Ignacio Chávez. Publicado por Masson Doyma México S.A. Este es un artículo Open Access bajo la licencia CC BY-NC-ND (http://creativecommons. org/licenses/by-nc-nd/4.0/).

* Corresponding author. Domicilio: Calle Juan Badiano 1, Tlalpan, Belisario Dominguez Sección XVI, 14080 México, D.F., Mexico.

E-mail address: dargaray@gmail.com (D. Araiza-Garaygordobil). 


\section{Introduction}

Both in India and México, cardiovascular diseases constitute the first cause of death and potential years of life lost. Even when located in different continents and under completely different geographical, cultural and social contexts, close similarities exist between these two countries when facing the difficulties to establish a universal reperfusion program for ST elevation myocardial infarction (STEMI). This paper describes the situation of STEMI treatment in both nations and explores the lessons that Mexico's health care system could adopt from the recent advances accomplished by the initiative STEMI India.

\section{The burden of cardiovascular disease and STEMI in India}

Despite the great economical growth that India has undergone during the last two decades, and a remarkable progress in reducing both, child and adult mortality, the treatment of non communicable diseases still represents a challenge for the Indian health care system. The burden that ischemic heart disease poses is bigger than in any other country in the world ${ }^{1}$ : it affects approximately 65 million people, and is a major contributor to death and disability, with and overall prevalence that has dramatically risen over the last 20 years. $^{2}$

The incidence of STEMI is higher in India when compared to other countries, and results in a higher mortality rate and subsequent morbidity. ${ }^{3}$ Moreover, Indians are more likely to develop coronary artery disease (CAD) at younger ages during an individual's working years, and as a result, there is an extremely high loss of potentially productive years of life in India. It is expected that nearly 18 million productive years of life are to be lost from CAD by 2013, a number that exceeds more than nine times that expected in the USA. ${ }^{2}$

Reasons underlying this problem are many. Among those, a reduced access to reperfusion therapy and its late administration (when available) are important problems to face while managing STEMI in India. Nation-wide, less than $10 \%$ get to receive reperfusion therapy by primary angioplasty, due poor availability and transportation delays. ${ }^{4}$ On the other side, those who manage to arrive early to the hospital have to deal with financing problems. Most of Indian patients pay out of pocket for emergency treatments, including care for STEMI and primary percutaneous coronary intervention $(\mathrm{PCl}) .{ }^{5}$ The fragmentation of health care system is also critical: most hospitals offering advanced cardiovascular interventions such as $\mathrm{PCl}$ are privately funded, and the public government-funded hospitals rely on state-driven coordination with little influence from central government.

With 29 states and seven union territories holding an immense cultural, geographical and idiom variation, the establishment of a nation-wide program for the timely and appropriate management of STEMI in this setting is a difficult and challenging task.

\section{The burden of cardiovascular disease and STEMI in México}

Likewise to what occurs in India, México has shown a remarkable progress in the eradication of communicable diseases like polio, neonatal and maternal mortality. ${ }^{6}$ However, ischemic heart disease constitutes the main cause of lost of years of life in the country. ${ }^{1}$ A high prevalence of coronary artery disease has been detected in Mexicans, especially with increasing age ${ }^{7}$ and with the high prevalence of cardiovascular risk factors in general population. . $^{8,9}$

Only in 2013, approximately 80,000 Mexicans died of myocardial infarction. ${ }^{10}$ Most of these patients were in economically productive years, and the impact brought by this loss to the nation's economy is substantial. The nation occupies the highest 30-day mortality for myocardial infarction among the Organization for Economic Cooperation and Development (OECD) members. ${ }^{11}$ With a nation-wide reperfusion rate of $52.6 \%$ and only $15 \%$ of the total STEMI patients undergoing primary $\mathrm{PCl},{ }^{12}$ the panorama of STEMI treatment in México remains distant to its North America neighbors USA and Canada.

The lack of a universal reperfusion program, an insufficient number of catheterization laboratories (available in only $15 \%$ of the hospitals, most of them not at all times), the fragmentation of the health care system and the poor capacity of primary care providers to properly recognize and initiate the management for STEMI may all contribute to this low rate of reperfusion. ${ }^{13}$

\section{Barriers to an effective reperfusion program for STEMI in low and middle income countries}

Unlike what's reported in randomized clinical trials and registries from developed nations, a multitude of barriers obstruct the pathway to a timely and universal reperfusion for STEMI in developing nations (Table 1).

Non-universal health system coverage is a major problem in both India and México: in India, the private medical sector remains the primary source of health care for $70 \%$ of households in urban areas and $63 \%$ of households in rural areas. ${ }^{14}$ México shows similar numbers, with a $54.6 \%$ of total health care expend allocated to private medical sector. ${ }^{15}$ According to the Organization for Economic Cooperation and Development (OECD), the fragmentation of the National Health System (NHS) in various organizations generates inefficiencies and inequities that affect the Federal government's efforts to achieve universal coverage, and impacting on its financial viability. ${ }^{16}$

In a system that lacks universal coverage and reimbursement, further access to high end specialty procedures (like coronary stents and fibrinolytics) is limited by the capacity of the patient to pay out-of-pocket for these. Specialty supplies like stents are billed to the hospitals as per the usage and then the hospitals add their profit share and bill the patients accordingly. This leads to a big gap between the buying price and the selling price to the patient, especially in privately owned hospitals, leading to a large escalation in the final price and limiting the access to these materials for a great quantity of patients. ${ }^{17}$

While much of the state of the art clinical practice around the world is based on guidelines, it is also important to recognize that such guidelines need to be altered to suit local requirements and fitting in with resources available in the developing world. While primary $\mathrm{PCI}$ has been recommended as the preferred reperfusion therapy in STEMI guidelines, ${ }^{18}$ 
Table 1 Similarities between India and México, regarding the care of STEMI.

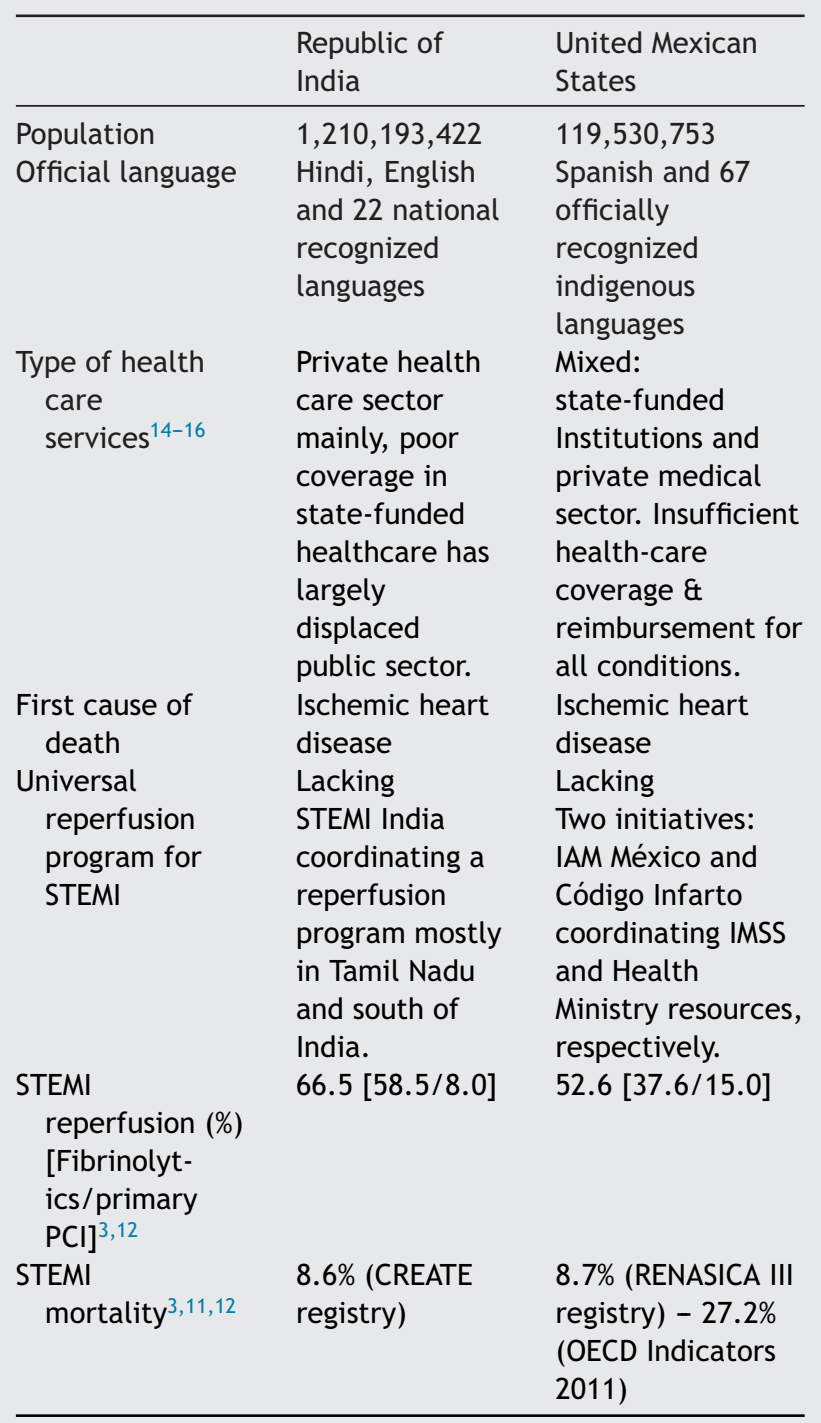

it is to be mentioned that this condition remains true provided that it can be performed expeditiously (i.e. within guideline mandated times), by an experienced team and regardless of whether the patient presents to a primary percutaneous coronary intervention $(\mathrm{PPCl})$ capable hospital.

Reperfusion with $\mathrm{PPCl}$ requires a coordinated system care and transport logistics which involves physicians, nursing staff, paramedic personnel and material resources; conditions that even in first world countries are not reached at all times.

Pharmacoinvasive strategy, an approach that bases on the widespread availability of fibrinolysis and its early administration to restore at least some degree of myocardial blood flow, coupled with the complete restoration of the culprit coronary artery that can be obtained with subsequent angioplasty may be a more suitable option for the reperfusion of STEMI in low to middle income countries. ${ }^{13}$

\section{STEMI India}

Beginning in early 2011, a non-profit initiative emerged in the region of Tamil Nadu. STEMI-India was born with the purpose of disseminate information, organize and train STEMI networks and develop systems of care for the appropriate management of STEMI in India.

Since its birth, several trials and scientific publications have been developed by or in coalition with STEMI-India. Among them, the Tamil Nadu-ST-Segment Elevation Myocardial Infarction Program (TN-STEMI) was a multicenter, prospective study using a preimplementation - postimplementation quasi-experimental design, developed as a part of a community-based treatment program. In brief, it instituted a hub-and-spoke model relying on an integrated network of 35 primary care health clinics and small hospitals (spokes) around $4 \mathrm{PCl}$-capable facilities (hubs) (Fig. 1). The Tamil Nadu State Government provided a comprehensive health insurance for among those below the poverty line. A public-private Emergency Management and ambulance services (with the ability to acquire and transmitting ECG's) was also available during the study. ${ }^{17}$

The recently published 1 year follow up results ${ }^{18}$ demonstrated that among the 2420 enrolled patients, rates of transfer from spoke health centers to hub hospitals was higher at the postimplementation phase.

While reperfusion rates remained high and similar in the pre and post implementation phases (88.5 vs $90.1 \%$ ), the rates of coronary angiography (35.0 vs $60.8 \%$ ), time to coronary angiography ( 39 vs $17 \mathrm{~h}$ ) and rates of reperfusion by $\mathrm{PCl}$ in spoke centers (3.1 vs $20.6 \%$ ) were better. Even when study was not designed as for detecting these results, a lower mortality for the postimplementation phase group was observed at 1 year follow up (17.6 vs $14.2 \%)$, with unadjusted odds ratio of 0.78 . Of note, these results were mainly driven by a mortality reduction in spoke hospitals (community hospitals and primary care facilities) and not in the large, $\mathrm{PCl}$-capable hub centers. Also of note, $48 \%$ of the enrolled patients in the TN-STEMI program were living below the poverty line.

\section{Stent price legislation in India}

Since July 2016, the health ministry of India placed stents as an item on the National List of Essential Medications. In February 2017, India's National Pharmaceutical and Pricing Authority (NPPA) made a landmark decision to fix ceiling prices for coronary stents to an equivalent of $\$ 108$ and $\$ 444$ USD for BMS and DES, respectively. This decision by the NPPA brought immediate price cuts and has been lauded by consumers and patients, but has drawn criticism from those concerned for shortages and stifle innovation. ${ }^{19,20}$

While this maneuver from the NPPA has been criticized, there is no question that it closes the gap between the financial issues and access to the best treatment possible.

\section{Which lessons could be learnt from STEMI India?}

Facing all sorts of difficulties, STEMI India initiative has managed to coordinate pre-hospital emergency services, 


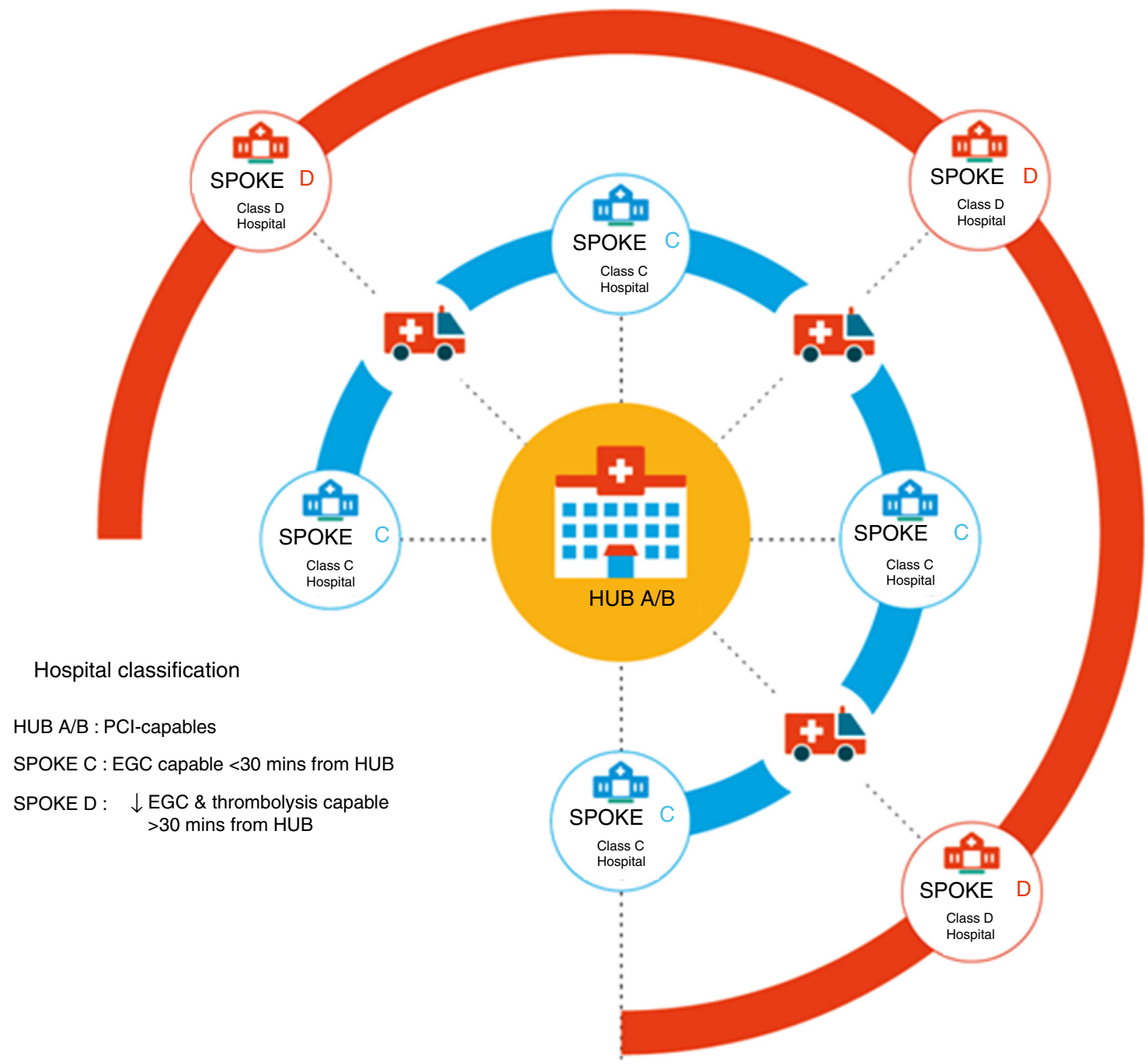

Figure 1 The TN-STEMI hub and spoke model of a system of care for myocardial infarction. Courtesy of Dr. Mullasari AS.

governmental resources, and the clinical practice of several public-private health care centers, with the necessary human and technologic resources to do it in an effective manner. Such efforts are to be recognized, and prove that establishing a universal reperfusion program against adverse conditions is possible.

The TN-STEMI trial has become a pivotal study for the developing of STEMI systems of care in low to middle income countries, as it demonstrated that the institution of a system, leads to a reduction in mortality and major cardiovascular events. Mexican health care system could learn from many lessons revealed by the experience of STEMI India: the adoption of a unique and dedicated ambulance emergency system, the partnership between public and private practices, bilateral agreement with state and federal government, local coordination with primary, secondary and tertiary health care centers and the use of high end technology manufactured by local companies.

\section{Funding}

No endorsement of any kind received to conduct this study/article.

\section{Conflict of interest}

The authors declare no conflict of interest.

\section{Acknowledgements}

The realization of this joint article was possible thanks to the support of the Consejo Nacional de Ciencia y Tecnología (CONACYT) through the program "Becas mixtas para especialidades médicas 2017, estancia en el extranjero", delivered to the first author.

\section{References}

1. GBD 2013 Mortality and Causes of Death Collaborators. Global, regional and national age-sex specific all-cause and causespecific mortality for 240 causes of death, 1990-2013: a systematic analysis for the Global Burden of Disease Study 2013. Lancet. 2015;385:117-71.

2. Alexander T. STEMI in India. Eur Heart J. 2016;37:2449-53.

3. Xavier D, Pais P, Devereaux PJ, et al. Treatment and outcomes of acute coronary syndromes in India (CREATE): a prospective analysis of registry data. Lancet. 2008;371:1435-42. 
4. Dalal JJ, Alexander T, Banerjee PS, et al. 2013 consensus statement for early reperfusion and pharmaco-invasive approach in patients presenting with chest pain diagnosed as STEMI (ST elevation myocardial infarction) in an Indian setting. J Assoc Physicians India. 2014;62:473-83.

5. Victor SM, Gnanaraj ASV, Pattabiram S, Mullasari AS. Door-toballoon: where do we lose time? Single centre experience in India. Indian Heart J. 2012;64:582-7.

6. Esteve-Jaramillo A, Richardson López-Collada VL. Towards the eradication of poliomyelitis: Mexico's achievements and challenges. Salud Publica Mex. 2012;54:537-43.

7. Posadas-Romero C, López-Bautista F, Rodas-Díaz MA, et al. Prevalence and extension of coronary artery calcification in cardiovascular asymptomatic Mexican population: Genetics of Atherosclerotic Disease study. Arch Cardiol Mex. 2017, http://dx.doi.org/10.1016/j.acmx.2016.12.004 [Epub ahead of print].

8. Acosta-Cázares B, Escobedo-de la Peña J. High burden of cardiovascular disease risk factors in Mexico: an epidemic of ischemic heart disease that may be on its way? Am Heart J. 2010;160:230-6.

9. Alegre-Díaz J, Herrington W, López-Cervantes $M$, et al. Diabetes and cause-specific mortality in Mexico City. N Engl J Med. 2016;375:1961-71.

10. Instituto Nacional de Estadística, Geografía e Informática. Mortalidad. [2016] México: www.inegi.org.mx [accessed 08.08.16]. Available from: http://www.inegi.org.mx/est/ contenidos/proyectos/registros/vitales/mortalidad/tabulados/ ConsultaMortalidad.asp

11. OECD. Health at a glance 2011: OECD indicators. OECD Publishing; 2011.
12. Martinez-Sanchez C, Borrayo G, Carrillo J, et al. Clinical management and hospital outcomes of acute coronary syndrome patients in Mexico: The Third National Registry of Acute Coronary Syndromes (RENASICA III). Arch Cardiol Mex. 2016;36:221-324.

13. Martínez-Sánchez C, Arias-Mendoza A, González-Pacheco H, et al. Reperfusion therapy of myocardial infarction in Mexico: a challenge for modern cardiology. Arch Cardiol Mex. 2017;87:144-50.

14. International Institute for Population Sciences and Macro International. "National Family Health Survey (NFHS-3), 2005-06". Ministry of Health and Family Welfare, Government of India; 2007:436-440.

15. Dantés OG, Sesma S, Becerril VM, et al. Sistema de salud en México. Salud Pub Mex. 2011;53:220-32.

16. Ares-Parga R. Proposal for an structural reform for the national health system. Gac Med Mex. 2011;147: 475-81.

17. Alexander T, Mullasari AS, Narula J. Developing a STEMI system of care for low- and middle-income countries: the STEMI-India model. Glob Heart. 2014;9:419-23.

18. Alexander T, Mullasari AS, Joseph G, et al. A system of care for patients with ST-segment elevation myocardial infarction in India: The Tamil Nadu-ST-Segment Elevation Myocardial Infarction Program. JAMA Cardiol. 2017;2: 498-505.

19. Wadhera $P$, Alexander T, Nallamothu BK. India and the coronary stent market: getting the price right. Circulation. 2017; 135:1879-81.

20. Kaul U. The new pricing policy for coronary stents in India: a boon or a bane? Eurolntervention. 2017;13:267-8. 